* Cómo citar esta entrevista: Sánchez Lopera, A. y Escobar Chacón, J. D. (2021). Colombia inmanente: conversación con Jorge Mario Múnera sobre su encuentro con Carlos Rincón. Estudios de Literatura Colombiana 48, pp. 115-124.DOI: https://doi.org/10.17533/ udea.elc.n48a06

1 https://orcid.org/0000-0003-1602-2071 als219@pitt.edu

University of Pittsburgh, United States

2 https://orcid.org/0000-0001-6664-3509 jdescobarc@unal.edu.co

Universidad Nacional de Colombia (sede Bogotá), Colombia
Editores: Andrés Vergara Aguirre, Christian Benavides Martínez, Valentina Noreña Gómez

Recibido: 15.02 .2020

Aprobado: 28.10.2020

Publicado: 18.12 .2020

Copyright: (2021 Estudios de Literatura Colombiana. Este es un artículo de acceso abierto distribuido bajo los términos de la Licencia Creative Commons AtribuciónNo comercial - Compartir igual 4.0 Internacional

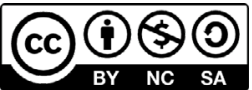

\section{Colombia inmanente: CONVERSACIÓN CON JORGE MARIO MÚNERA SOBRE SU ENCUENTRO CON CARlos Rincón*}

\author{
Immanent Colombia: A Conversation \\ with Jorge Mario Múnera about his \\ meEting With Carlos Rincón
}

Alejandro Sánchez Lopera, ${ }^{1}$ Juan David Escobar Chacón ${ }^{2}$

Hemos perdido el tiempo con sutilezas inútiles para saber si la fotografía es un arte o no, sin preguntarnos antes si la fotografía no había trastornado por completo el carácter del arte

Walter Benjamin

Jorge Mario Múnera (Medellín, 1953) es, junto con Nereo López y Jesús Abad Colorado, quien más lúcidamente ha retratado, en una suerte de “prosa apátrida” según sus palabras, el semblante de ese cuerpo social colombiano poblado de retazos y márgenes. Además es uno de los exponentes latinoamericanos más destacados de lo que él mismo llamó la gran innovación editorial del siglo xx: el libro fotográfico. Múnera, en tanto testigo visible de lo invisible, captura aquello que, a fuerza de ser olvidado y reprimido, no cesa de retornar por doquier en imágenes. Sus fotografías son como una madeja de hilo que flota sobre "el mar de amnesia" - sus palabras - en el que chapalea a diario $\mathrm{Co}^{-}$ lombia. Al obturar, Múnera nos expone a instantáneas obstinadas, inmersas en una duración que no es la de la conmemoración, sino la del afuera. Para 
usar la palabra de Carlos Rincón, son parte del centón inmemorial de los olvidados. Antes que conformar un archivo monumental, sus retratos son legajos disímiles que operan como una contramemoria del futuro.

En esta entrevista Múnera relata su encuentro con Carlos Rincón, quien incluyó varios de sus retratos en sus dos últimos libros. Retratos que, precisamente, re-traen aquello que ha sido despreciado: el Bolívar des-hecho, fragmentado como esa Colombia republicana imposible, poblada por "los países de Colombia" de Aurelio Arturo, "silencioso, maltrecho, agredido, derrotado, mirando la ciudad enemiga", como cuenta en esta entrevista, un Bolívar por armar.Jorge Mario Múnera ganó el Premio Nacional de Fotografía (1999) y el Latino and Latin American Art Forum Prize de Harvard University (2003). Gracias a este último reconocimiento, publicó Portraits of an Invisible Country (Harvard University, 2010), editado por José Luis Falconi. En su contribución a esta obra, titulada “The Marco Polo Connection”, Carlos Rincón entrevera el título del libro de Múnera con el de Las Ciudades invisibles de Calvino y se pregunta: “¿Para quién son posibles los retratos sin rostro?”. Ese país invisible, anónimo, que retrata Múnera, es virtual — pero no por ello menos real—. Es la Colombia inmanente que transcurre en el encuentro entre Múnera y Rincón.

Carlos Rincón y usted tuvieron una amistad que duró décadas, forjada en la fascinación por la fotografía y su capacidad de abrir nuevos horizontes de interpretación. ¿Podría contarnos cómo conoció a Rincón y qué interés particular tenía él en la fotografía? ¿Qué aportó el profesor Rincón a su trabajo como fotógrafo?

Conocí a Carlos Rincón en 2005. El Centro Rockefeller de Estudios Latinoamericanos de la Universidad de Harvard decidió publicar una serie de libros sobre algunos de los trabajos ganadores del Programa Art Forum. Portraits of An Invisible Country, de mi autoría, fue el título escogido para iniciar la serie. José Falconi, editor del libro, invitó a Carlos Rincón, que era profesor visitante, a participar en el dosier crítico. El aceptó y así nos conocimos. Su grata conversación me produjo un fuerte y delicioso efecto anestésico que le permitió hacerme una vivisección minuciosa mientras yo veía con alivio y gozo cómo me iba desarmando. Era tanta su atención como la precisión de sus preguntas 
y ni qué decir de esa curiosidad insaciable que nutría un vertiginoso caudal de libre asociación y análisis crítico. The Marco Polo Connection es el título del ensayo que escribió sobre ese primer encuentro. Luego seguimos viéndonos cada vez que él pasaba por Bogotá, pues de nuestras conversaciones surgieron muchos cabos que atar y algunas colaboraciones puntuales en sus proyectos.

Desde las primeras charlas sentí un intenso interés de su parte tanto por la historia de las personas y los objetos fotografiados como por la vida de los fotógrafos, el contexto socioeconómico y político de sus actividades, todo dirigido a comprender - y cito sus palabras - "la relación con los usos normativos de la imagen a través de su trabajo".

Sin duda su procedimiento analítico tenía todo el rigor crítico y, además de la impresionante y generosísima solidez académica, gozaba de una gran elasticidad para abordar las temáticas por flancos inéditos, una intuitiva y a la vez sabia capacidad de asociación de todos los elementos disponibles sobre el asunto tratado. Esto le permitía entender y aclarar el sentido de mis actos fotográficos desarrollados en el curso documental de los sucesos, sustentados en hallazgos y apariciones, en el reconocimiento de estructuras visuales o en la creación de imágenes.

Durante casi cuatro décadas estuve inmerso en la realización de series fotográficas sobre muy distintas temáticas colombianas, pero en la dinámica de esos años solo tuve tiempo para viajar, revelar y guardar todos esos materiales. Fue el requerimiento curatorial de Art Forum lo que me obligó por primera vez a revisar el archivo acumulado, a empezar a pulir esa piedra en bruto. Gracias a la fascinante capacidad del profesor Rincón para leer la imagen y descifrar sus narrativas concatenadas, pude entender el sentido general de mi trabajo y las relaciones existentes entre las obras que había producido hasta entonces.

En sus últimos años, Rincón se dedicó a estudiar la genealogía de la memoria cultural en el país. En ese sentido, la imagen de portada de su libro Retratos de un país invisible, en la que aparece un Simón Bolívar corroído por el tiempo, muy lejano de la figura épica que se intentó construir por más de doscientos años, parece ser clave en la interpretación de Rincón sobre algunos procesos culturales en Colombia. ¿Podría explicarnos un poco la historia de esta fotografía? 
Sí, este es un caso que lo retrata. Una tarde de enero de 1990 yo iba caminando por las afueras de Pasto, en busca de un panadero célebre por hornear panes antropoformos, algunos de tamaño natural. Quería encargarle y verle hacer uno de $178 \mathrm{~cm}$ a partir de la foto de mi novia. Un chubasco me obligó a buscar refugio en el alero de una pequeña capilla doctrinera que estaba justo al paso y, al buscar mejor protección, me moví hacia el trasaltar y ahí estaba Simón Bolívar a la intemperie, tallado en un tronco de casi cuatro metros de alto por uno de diámetro, silencioso, maltrecho, agredido, derrotado, mirando la ciudad enemiga.

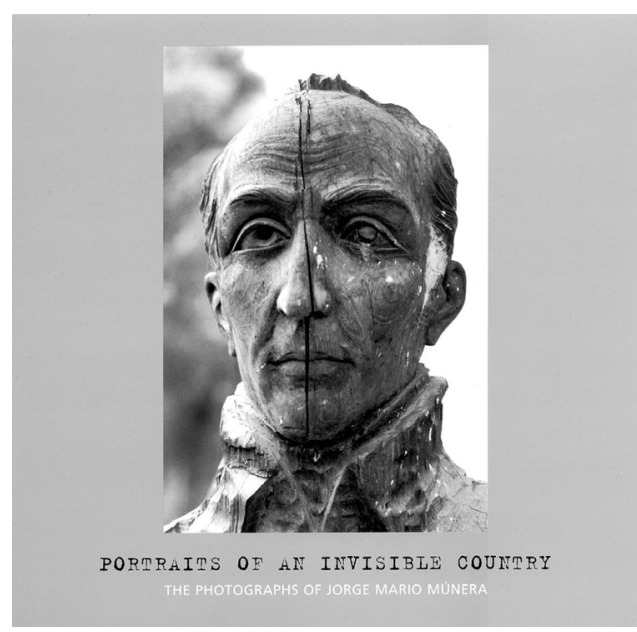

Imagen tomada de https://bit.ly/3kYwnwk

Cuando Carlos vio este retrato se emocionó mucho. La polisemia de esa imagen le permitía reflexionar desde cualquiera de sus detalles; era un artefacto adecuado a su ergonomía intelectual, un territorio que podía recorrer y desandar todas las veces que quisiera. En nuestras conversaciones sobre este retrato - y lo digo así, pues al ver a Bolívar envuelto en la bruma andina supe que era la ocasión de hacer esa sesión fotográfica que tanto había imaginado y que el tiempo y la racionalidad jamás me habrían permitido-, Carlos reconstruía los diferentes recorridos que me habían llevado a ese instante: quería saber todo al respecto como si en cada detalle pudiera estar la clave para descifrar ese encuentro irrepetible.

Pero, ¿quién habría labrado esa talla? ¿De cuál de los maravillosos talleres de madera de Pasto habría salido esa obra? ¿La traerían de Quito, tierra de ebanistas? ¿Sería obra de algún habitante de Obonuco o Jongovito? Durante años Carlos me preguntó si sabía algo nuevo que nos ayudara a averiguarlo, alguna pista que le permitiera encontrar al autor.

El profesor iba con frecuencia a Pasto a dictar algunos de sus seminarios en la universidad, y al regresar de uno de ellos — creo que en 2014 — recibí una 
llamada suya en la que me pedía vernos de inmediato. Al encontrarnos, me dijo: "Tengo un regalo para ti”, y me extendió un sobre con los documentos de un increíble hallazgo.

Durante su estadía, Carlos había visitado el famoso taller de ebanistería y talla de la familia Zambrano, a quienes yo había conocido en 1983 cuando hice un documental sobre los artesanos pastusos. A Carlos le fascinó ese taller y en una estantería le llamó la atención un ejemplar titulado Progreso Nariñense. Monografía y guía comercial ilustrada del Departamento de Nariño, 1938. Ahí encontró una página dedicada a Antonio Durán Sánchez, escultor y fotógrafo, con dos fotos: la primera es un retrato del artista, y en la otra se ve a Durán en su taller rodeado de obras. Cerca de él, a su lado, está la escultura del Bolívar que lo dobla en altura. Así fue como el profesor Rincón identificó al autor de la talla, un fotógrafo escultor tuquerreño que nadie podría haber imaginado para cerrar la historia de ese retrato.

Una de sus obras más reconocidas es “Orfebrería y chamanismo" (1990). Esta obra fue de gran relevancia en el campo de la antropología y la arqueología debido a que "reveló" aspectos que pasaban desapercibidos por el público, gracias a un tratamiento particular de la luz a la hora de tomar las fotografías. Tenemos entendido que Rincón tuvo que ver en la interpretación que se le dio a estas imágenes.

Cuando conocí a Carlos, Orfebrería y chamanismo, con textos de Gerardo Reichel-Dolmatoff y fotografías mías, tenía ya quince años de publicado. Durante el trabajo con Reichel me di cuenta de que las ideas que él tenía sobre el oro precolombino requerían de una imagen a la medida de la maravillosa revelación de su texto sobre la iconografía del vuelo de las aves de oro, los chamanes y la mente, y su función como emblemas del mundo precolombino. No decidía cómo fotografiarlas hasta cuando el profesor Reichel me explicó, dibujando en unas servilletas, los íconos principales sobre los que íbamos a trabajar: así me di cuenta de que las piezas deberían ir — como en esos dibujos - sobre un fondo blanco sin sombras, en oposición a los fondos negros o de colores en boga, que teñían el color del oro con un tono dominante. Para ello opté por una iluminación suave, idéntica para todas las piezas, que permitiera apreciar la totalidad de 
superficie de los objetos, sin pérdida de detalle en altas luces ni en las sombras y que, a simple vista y por primera vez, evidenciara cómo no hay dos colores de oro iguales en la orfebrería precolombina. Era una forma radical de oponerse a la visión de El Dorado como un botín de joyas destellantes, un arrume de adornos cuyo único valor era el peso del metal, un tesoro expoliado a sangre y fuego guardado en oscuras bóvedas. ¡Nunca hay que olvidar que esas piezas fueron fundidas y despreciadas de forma sistemática durante casi cinco siglos!

Sobre el tema del oro y el Museo del Oro, Carlos venía preparando esa tremenda investigación titulada Consideraciones morales sobre el oro sagrado de los indios y el Museo del Oro del Banco de la República, que se centra en los antecedentes históricos y políticos en torno al tesoro precolombino y al surgimiento del museo. Más que una interpretación de las imágenes — que era lo que había hecho Reichel-Dolmatoff-, Rincón se ocupó de reflexionar sobre la lucha de poder en torno a este acervo y a precisar una serie de sucesos que han marcado el destino de dicha colección, incluido el intento de descuartizamiento y desaparición del texto de Reichel y de mis fotografías, tal como lo relata en detalle el profesor en el capítulo final de ese texto.

\section{E1 libro Avatares de la memoria cultural en Colombia: formas simbólicas} del Estado, museos y canon literario (2015) fue uno de los últimos que publicó Rincón. Empieza con un “Bestiario”. ¿Podría hablarnos de su relación con la literatura, y de la génesis de este proyecto y de su contribución al mismo?

Desde el inicio de mi vida de fotógrafo tuve claro que el conocimiento de las artes y ciencias, en particular el de las ciencias sociales, era fundamental. "Se ve lo que se sabe" podría ser la divisa. Solo en la fotografía encontraba la forma precisa de integrar imagen y palabra, sin necesidad de destreza manual ni del uso de géneros literarios. Este medio permitía hacer fotolibros, que me han fascinado desde el primero que tuve entre mis manos apenas adolescentes: un artefacto editorial recién inventado, hecho con un nuevo tipo de soporte visual y un nuevo tipo de escritura: el pie de foto. Vi esos primeros maravillosos libros en la librería Aguirre de Medellín, las ediciones príncipe de los que hoy son los clásicos de la fotografía. Todo esto en medio del boom, con Rulfo y Cor- 
tázar dinamitando los límites con sus extraordinarias fotos. Ellos, que fueron fotógrafos antes de empezar a escribir sus grandes novelas, me indicaron la inseparable intimidad de la fotografía y la escritura, y la profunda relación que existe entre fotografía y literatura latinoamericanas.

Con respecto a "Bestiario", el profesor Rincón tuvo la gentileza de invitarme a participar en el cuarto y último tomo de la reveladora Colección 2010 con la carátula y un portafolio temático. Hacía poco, en un viaje al Caquetá, en una casa huitoto del Resguardo Coropoya fotografié una serie de dibujos de héroes de la Independencia que me impresionaron tanto por su factura como por su relación con otros objetos de diversa índole, colgados cerca y alrededor en las mismas paredes. Me pareció que una de esas fotos, en la que están Bolívar y Santander rodeados de adornos festivos y serruchos, correspondía a la intención editorial de la publicación.

En cuanto al Bestiario, recuerdo que surgió revisando con el profesor dos de mis series: Memoria de festejos populares y Habitantes de los confines. Carlos señaló la presencia diseminada pero constante de fotografías donde los animales eran un elemento fundamental. Reuní esas imágenes y extendí la búsqueda al resto del archivo de manera que pude corroborar que este tema había estado presente sin que lo considerara una prioridad temática. Al entender que todos esos animales no estaban ahí por azar y requerían mucha más atención, decidí darle a la serie ese nombre genérico del cual Carlos me había hecho una larga relación de títulos medioevales. De hecho, por eso escogí ese capítulo para su libro, con una selección de fotografías de nuestra vida con los animales vivos, muertos o figurados.

La articulación de los investigadores y los trabajadores de la imagen se ha intensificado cada vez más. La alianza entre la academia y la fotografía debe escalar su eficacia. La fotografía debe ser aceptada y usada con la normatividad y rigor aplicados a las fuentes escritas, tal como lo hizo Rincón. Al hacerlo así, el profesor Rincón abrió un amplio espacio para sus investigaciones. Apenas empezamos a dimensionar su legado pero presiento que es más importante y profundo de lo que imaginamos. Es tan diverso, tan rico, tan osado su intento de crear una visión distinta de nuestra historia cultural, que necesitaremos el trabajo de muchos y un buen tiempo para entender la totalidad de su propósito. 
En la introducción al "Bestiario”, Rincón escribe lo siguiente: “Las series de fotografías de Jorge Mario Múnera son conceptos del mundo codificados en las imágenes de quien lo mira con la cámara, para despertar en quien las observa una mirada que se dirige hacia lo imaginario. Huellas del mundo, sus fotografías logran ser a la vez imágenes del recuerdo y de la imaginación, como si el mundo comenzara a existir con ellas". ¿Qué le devuelven al espectador estas fotografías?

A cada espectador lo suyo, pero para todos está disponible el artefacto fotográfico capaz de llevarnos a conocer los límites entre la ficción y la realidad, entre el recuerdo y la premonición, entre el olvido y el reconocimiento. Aunque las imágenes iniciales sean documentales, indiciales, hay cosas y hechos en ellas que abren un espacio alterno de ida y vuelta, en el que lo real se torna ficticio, y a la inversa. Hay una subversión de hecho: la inauguración de un mundo en el que es posible, al anular la fatalidad fisiológica del punto de vista, compartir el otro lado del espejo: el lugar, el tiempo, las cosas, los sucesos, las personas, reflejados en su azogue. Esas imágenes evanescentes son rastros de la búsqueda de un ser y de un lugar en el mundo. La coincidencia del fotógrafo y el fotografiado en un plano y la sincronía en un instante suceden en un mapa fractal que contiene nuestras vidas. La expresa voluntad de retratarse de los protagonistas confirma la conciencia de lo efímero y su secreta revelación.

Los que están vivos en mis fotos, salen muertos en las de otros. La violencia ataca a los cuerpos y a todo lo que encierran. La guerra arrasa la cultura popular así como los bombardeos calcinan el esplendor de las orquídeas nativas.

El archivo es también el testimonio de una pérdida, cenizas de un mundo desaparecido. Pero, a mi forma de ver, lo que permite la compresión de los conflictos y las tensiones de ese mundo desplazado por la violencia y las fuerzas de los procesos modernizantes a los que aludes, surge de la concatenación de la mayor cantidad posible de archivos creados durante una época determinada y no de la valoración artística de los más prominentes. De todas maneras los archivos fotográficos colombianos están marcados por el conflicto y la violencia, incluidos aquellos en los que no hay ni una gota de sangre. Esta memoria visual contiene datos suficientes para precisar el quién, cómo, cuándo y dónde; ¿jpero bastará esto para determinar el qué y el por qué? La violencia agrava el asunto. ¿Qué 
es lo que se pierde para siempre? Me agobia en extremo eso que se llevan los muertos, en especial los desaparecidos y los asesinados. He intentado que mis fotografías sean testimonio de lo que nos quita el exterminio.

En el conversatorio del 31 de octubre de 2019 en la Universidad Nacional, usted nos habló de la falta de archivos fotográficos en el país. De alguna manera, esto resulta en un impedimento para reconstruir la historia de la fotografía en Colombia y de la mirada fotográfica. ¿Qué importancia tienen estos archivos para la comprensión de nuestra memoria y nuestras literaturas?

Más que a una falta de archivos me refería a la carencia de procedimientos metodológicos de investigación y de un sistema de información adecuado para la historia de la fotografía en este país. De cierta forma, el archivo fotográfico colombiano tiene muchos desaparecidos... que nadie busca; carece de datos sobre el sector fotográfico, de su conformación social y de su economía. La memoria fotográfica organizada que existe es invaluable pero de difícil acceso. En ese archivo latente está una fuente esencial e inédita de nuestra historia reciente, lo que es una grave limitación para el trabajo investigativo. Sueño una fototeca digital colombiana que dé acceso a las colecciones actuales.

En Colombia la ausencia de la imagen de los escritores es notoria. Prácticamente los escritores que se reconocen son muy pocos, García Márquez y Mutis y dos o tres más, pero del resto es poco lo que existe; sería necesario mostrar fotos de Aurelio Arturo, Cote Lamus, Gaitán Durán y tantos otros en una misma publicación... No hay una relación directa o proporcional entre el conocimiento de las obras y el de la persona o la imagen de la persona que la crea, como si el escritor fuera un nombre sin cuerpo. Un cuerpo que solo se lo devolverá la fama. A mí me parece increíble que siendo este un país de poetas y de escritores no hayamos hecho hasta hoy un ensayo fotográfico de autor, sobre una lista rigurosa de los escritores vivos. Obviamente ahí sucede algo raro, no sé si sea un ocultamiento deliberado, una tendencia genética a la amnesia, un descuido, o que sencillamente no le ha importado a nadie.

La academia entonces se interesa cada vez más en la fotografía como referencia, pero solo en pocos casos se valora como fuente principal, a la par que 
la fuente escrita. La polisemia del lenguaje fotográfico desborda con frecuencia el canon investigativo y dificulta su aceptación probatoria y su uso bibliográfico, como si el discurso político primara sobre el científico y esto inhibiera su validez académica. En buena parte mi trabajo ha sido fotografiar lo que las palabras me han enseñado; acceder al mundo desde el lenguaje fotográfico y situar su discurso en el meollo de la investigación académica y el debate intelectual. Es así como se va construyendo un archivo fotográfico hecho de recortes de la realidad y sus circunstancias, de los poderes de la imaginación y del testimonio autobiográfico. Su sincronía es la crónica alternativa que le propone la fotografía a las ciencias y a las artes, y la dosificación de cada una de esas partes — historia, imaginación y aventura vital— son el arte y estilo del fotógrafo. 